\title{
In-vivo Evaluation of Anti-urolithiatic Activity of Different Extracts of Peel and Pulp of Cucumis melo L. in Mice Model of Kidney Stone Formation
}

\author{
Aneeqa Saleem ${ }^{1}$, Muhammad Islam ${ }^{1}$, Hamid Saeed ${ }^{1 *}$ and Mehwish Iqtedar ${ }^{2}$ \\ ${ }^{1}$ University College of Pharmacy, University of the Punjab, Allama Iqbal Campus, \\ 54000, Lahore, Pakistan \\ ${ }^{2}$ Department of Biotechnology, Lahore College for Women University, Jail Road, \\ Lahore, Pakistan
}

\section{A B S T R A C T}

The aim of the present study was to investigate the in vivo anti-urolithiatic effects of both peel and pulp extractives of Cucumis melo L., in mice model of nephrolithiasis. Extractives of peel and pulp were obtained using hot and cold methods. Ethylene glycol $(0.75 \% \mathrm{~V} / \mathrm{V})$ was used IP for 10 days to develop mice model of nephrolithiasis. Extracts were administered at a dose of $400 \mu \mathrm{g} / \mathrm{g}$ for $11-21$ days. Outcome measures included serum creatinine, uric acid and BUN levels. Significant differences exist with regards to primary and secondary metabolites between both peel and pulp extractives. After 21 days of treatment in mice, only chloroform (CHL) extractives of peel and pulp demonstrated significant improvements in serum creatinine (Peel: N; $1 \pm 0.44$, PC; $1.4 \pm 0.62$, CHL; 0.43 $\pm 0.18, p<0.05$, Pulp: CHL; $0.8 \pm 0.26, p<0.05$ ) and BUN levels (Peel: N; 13.2 \pm 0.53 , PC; 9.1 \pm 0.97 , CHL; 9.4 $\pm 0.84, p<0.05$, Pulp: $10.5 \pm 0.7, p=0.05$ ) compared to positive and normal controls, respectively. Moreover, uric acid levels were improved by methanol extract of peel $(\mathrm{MeOH} ; 4.8 \pm 0.4, p<0.05)$ and chloroform extract of pulp (PC; $7.1 \pm 0.4 \mathrm{CHL}$; $6.2 \pm 0.7, p<0.09$ ). Out of all the extractives of Cucumis melo L. peel and pulp, only chloroform extract exhibited significant anti-urolithiatic activity as evident from serum creatinine, uric acid and BUN levels.
\end{abstract}

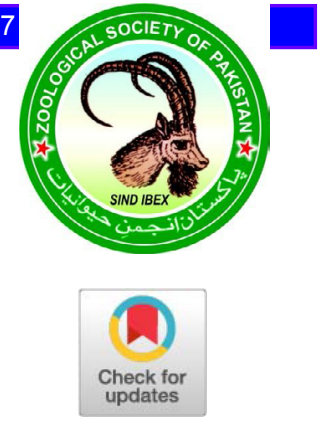

Article Information

Received 18 April 2019

Revised 25 July 2019

Accepted 11 January 2020

Available online 04 June 2021

Authors' Contribution

AS performed the experiments and prepared first draft. MI designed and supervised the study and provided resources. HS performed mice experiments, wrote the manuscript and supervised the study. MIQ analyzed the data and edited the manuscript.

Key words

Anti-urolithiatic, Cucumis melo L.,

Nephrolithiasis, Peel, Pulp

\section{INTRODUCTION}

U rolithiasis, characterized by the presence of solid non-metallic minerals in urinary tract, is the third most common disorder of urinary system after urinary tract infection and pathological conditions of prostate (Jagannath et al., 2012). Untreated urinary calculi can lead to serious complications such as extreme obstruction, hyderonephrosis, infection and hemorrhage in urinary tract system (Khoei et al., 2009). Notable procedures for its management include surgical operation, lithotripsy and use of high power laser to disrupt local calculus (Makasana et al., 2014; Pawar and Vyawahare, 2015). Over the past few years, the incidence of kidney stones has substantially increased. Urolithiasis is widely distributed disease mainly in industrialized countries (Ahmed et al., 2016). Kidney stone formation is still a mystifying disease despite extensive research in urology, thus requires both preventive and curative therapies for better management and treatment outcomes. At present, no appropriate

\footnotetext{
* Corresponding author: hamid.pharmacy@pu.edu.pk 0030-9923/2021/0004-1435 \$ 9.00/0

Copyright 2021 Zoological Society of Pakistan
}

modern drug therapy exist which can prevent kidney stone formation or can dissolve the stones, thus still many entrust on alternative systems of treatment (Wright et al., 2007).

Various therapeutic strategies and their combinations have been used for the management of urolithiasis, such as diet, diuretics, expulsion therapy, chelating agents and probiotic therapy (Galib et al., 2006). Nevertheless, the surgical removal of kidney stones still remains the mainstay treatment for urolithiasis. Modalities, such as extra corporeal shock wave lithotripsy (ESWL) has widely been used for the treatment of urolithiasis (Rafiq et al., 2012) but is associated with further complications such as renal injury, traumatic effects, presence of residual stone fragments, infection and likelihood of new stone formation (Musa et al., 2007). Likewise, percutaneous nephrolithoctomy (PCNL) is also considered a valuable treatment for the complete removal of stones with numerous benefits, such as lower morbidity, shorter operative time, shorter hospital stay and earlier return to normal life but does not ensure the determent of stone recurrence (Knoll, 2010). Thus, patients are more likely to incline towards herbal remedies to reduce kidney stones as it is safe and reliable treatment known to them. Several literature evidences suggested that Cucumis melo 
L. possesses lithiotriptic activity in addition to several other activities such as diuretic, detergent, demulcent, and as a cooling medicine in burning micturition and oliguria (Zaman et al., 2017; Varghese et al., 2013; Lakshmi, 2014). Geographically, native and exotic range of $C$. melo is widely distributed in Iran, Pakistan, India, Indonesia, Japan, Srilanka, China and Saudi Arabia. Traditional uses include, regulation of kidney functions, reduction in blood pressure, dyspepsia, flatulence, leprosy, jaundice, constipation, anemia, diabetes, obesity, amentia and menorrhagia (Asif et al., 2014). Cucumis melo is a useful remedy in the management of Alzheimer's disease which has been attributed to the presence of several natural compounds including flavonoids, linoleic acid, arachidonic acid (regeneration of cholinergic neurons), phosphatidylethanolamine and phosphatidylcholine (precursor of acetylcholine) and linoleic acid that increases the release of neuro-protectin D1 (neuro-protective role) (Parle and Singh, 2012). Despite so many uses of C. melo explored so far, the in-vivo effects of the extracts of peel and pulp of $C$. melo in preventing kidney stones formation and improving kidney functions still remain unexplored. Thus, the present study examined the in-vivo effects of extracts of peel and pulp of C.melo in ethylene glycol induced kidney stone mouse model.

\section{MATERIALS AND METHODS}

\section{Plant material, chemicals and reagents}

In April, 2016, about $60 \mathrm{~kg}$ of melon fruit was purchased from a local vendor in Lahore. Plant was authenticated under voucher no. GC. Herb. Bot. 2960 from the Department of Botany, Government College University, Lahore, Pakistan. The fruits were peeled off and cut into pieces and sun dried for almost 2 weeks. The dried peel and pulp material was collected and pulverized separately by mechanical grinder.

Following chemicals and reagents/solvents of analytical grade were used; Petroleum ether (SigmaAldrich), Chloroform (MAY and BAKER LTD), acetonitrile, deionized water, methanol, ethanol, acetic acid, ethyl acetate, ethanol, n-butanol, n-hexane(all from E. Merck A.G. Darmstadt, Germany), acetone, hydrochloric acid, sulphuric acid, nitric acid (BDH, England), sodium carbonate, sodium hydroxide, copper sulphate (E. Merck A.G. Darmstadt, Germany), potassium sodium tartrate $(\mathrm{BDH}$, England), potassium acetate, gallic acid (Sigma Life Science, Germany) aluminum nitrite (E. Merck A.G. Darmstadt, Germany), quercetin (QTN) and anhydrous glucose (E. Merck A.G. Darmstadt, Germany).
Physicochemical analysis of powdered peel and pulp of Cucumis melo $L$.

The moisture content, total ash, acid insoluble ash, water soluble ash, sulphated ash and extractive values, alcohol and water soluble, were estimated according to USP procedures (USP, 2005).

\section{Extraction of Cucumis melo L. peel and pulp}

Different solvents including petroleum ether, chloroform, methanol, ethanol and water were used for extraction. Hot extraction was done by soxhlet apparatus using n-hexane, chloroform and methanol, while cold extraction was done by maceration using ethanol and water (Saleem et al., 2018).

\section{Determination of primary and secondary metabolites}

Primary metabolites which include total proteins, lipids and carbohydrates were estimated according to protocols described previously (Lowry et al., 1951). While, secondary metabolites including total polyphenols, flavonoids, polysaccharides and glycosaponins were measured according to the protocols explained previously (Chang et al., 2002; Slinkard and Singleton, 1977).

Animals

Male mice weighing 20-30g were maintained in animal house at University College of Pharmacy, Punjab University, Lahore, Pakistan. All animals were kept at room temperature $\left(25 \pm 1^{\circ} \mathrm{C}\right)$ and relative humidity of $45-55 \%$. All mice were maintained on standard laboratory chow with ad libitum (as much as) access to food and water.

\section{Ethylene glycol induced urolithiasis mouse model}

Pilot study was performed on five albino mice to induce kidney stones by intra-peritoneal administration of ethylene glycol $(0.75 \% \mathrm{~V} / \mathrm{V})$. Baseline values of serum creatinine, uric acid and BUN were estimated before injecting ethylene glycol. After ethylene glycol injections, at day 10 , urolithiasis was confirmed by measuring serum creatinine, uric acid and BUN levels.

Study design for the assessment of urolithiatic activity of Cucumis melo $L$.

Ethylene glycol induced urolithiasis model was used to assess the antilithiatic activity in mice. Mice were randomly divided into 5 main groups $(n=5)$ with further sub-divisions of groups IV and V with 5 mice in each main and sub-groups.

Group I consisted of normal mice supplemented with vehicle only. Group II (positive control) consisted of standard drug - a remedy for kidney stone, i.e., Cystone syrup $(5 \mu \mathrm{g} / \mathrm{g})$. Group III (negative control) consisted of 
ethylene glycol $(0.75 \% \mathrm{~V} / \mathrm{V})$ treated urolithiasis mice for 21 days.

Kidney stone inhibition activity of peel and pulp extracts of Cucumis melo L. were examined in mice divided into two main groups. Group IV (peel extracts) with further sub-division into IVa; mice treated with petroleum ether extract, IVb; mice treated with chloroform extract, IVc; mice treated with ethanol extract, IVd; mice treated with aqueous extract, all at a dose of $400 \mu \mathrm{g} / \mathrm{g}$ of the body weight - 11 to 21 days of activities.

Group V (pulp extracts) further sub-division in to Va; mice treated with petroleum ether extract, $\mathrm{Vb}$; mice treated with chloroform extract, Vc; mice treated with ethanol extract, $\mathrm{Vd}$; mice treated with aqueous extract, all at a dose of $400 \mu \mathrm{g} / \mathrm{g}$ of the body weight - 11 to 21 days of activities.

All doses were prepared fresh the same day in sterile PBS from the stock. Mice were weighed before intraperitoneal administration of doses daily as per the body weight $-400 \mu \mathrm{g} / \mathrm{g}$ of the body weight.

\section{Assessment of urolithiatic activity and serum analysis}

After the experimental period, i-e., on day 21, the blood samples were collected by cardiac puncture for all the test mice under general anesthesia, and later sacrificed by cervical dislocation. Serum was separated by centrifugation at $10,000 \mathrm{rpm}$ for $10 \mathrm{~min}$ and analyzed for creatinine, uric acid and BUN.

\section{Statistical analysis}

The results were expressed as mean \pm SD. The statistical significance between two groups were estimated by two-tailed student's t test, paired, while significance levels among multiple groups were assessed using one way analysis of variance (ANOVA). An alpha value of 0.05 of less was considered statistically significant.

\section{RESULTS}

Proximate analysis of extracts of Cucumis melo $L$.

Various physiochemical analysis of Cucumis melo L. peel and pulp are summarized in Table I. Data suggested that the moisture content was within the acceptable limits for both peel and pulp extracts, i-e., $5.18 \pm 0.035$ and $5.36 \pm 0.04$, respectively. Additionally, data suggested high values for alcohol soluble extractives with almost minimal differences between peel and pulp extractives, i.e., $39.77 \pm 0.10$ and $36.41 \pm$ 0.05 , respectively. However, water soluble extractives exhibited significant differences between peel and pulp, much higher extractive values for peel, $51.53 \pm 0.40$, compared to pulp, $22.66 \pm 0.15$ (Table I).
Table I. Physicochemical analysis of powdered peel and pulp of Cucumis melo L.

\begin{tabular}{llll}
\hline $\begin{array}{l}\text { Sr } \\
\#\end{array}$ & Analytes & $\begin{array}{l}\text { Percentage } \\
\text { contents in } \\
\text { peel } \pm \text { SD }\end{array}$ & $\begin{array}{l}\text { Percentage } \\
\text { contents in } \\
\text { pulp } \pm \text { SD }\end{array}$ \\
\hline $\mathbf{1}$ & Moisture content & $5.18 \pm 0.035$ & $5.36 \pm 0.04$ \\
2 & Total ash & $9.5 \pm 0.4$ & $16.04 \pm 0.03$ \\
3 & Acid insoluble ash & $0.416 \pm 0.02$ & $0.866 \pm 0.25$ \\
4 & Sulphated ash & $12.43 \pm 0.503$ & $17.45 \pm 0.05$ \\
5 & Alcohol soluble extractive & $39.77 \pm 0.10$ & $36.41 \pm 0.05$ \\
6 & Water soluble extractive & $51.53 \pm 0.40$ & $22.66 \pm 0.15$ \\
\hline
\end{tabular}

Phytochemical screening of extracts of Cucumis melo $L$.

Percentage content of powdered peel and pulp of the plant are summarized in Figure 1A-C. The amount of primary metabolites, total lipids, carbohydrates and proteins, were significantly different between peel and pulp. It was observed that total proteins were much higher in pulp of the plant, while total lipids and carbohydrates were significantly higher in peel pf the plant (Fig. 1A-C).
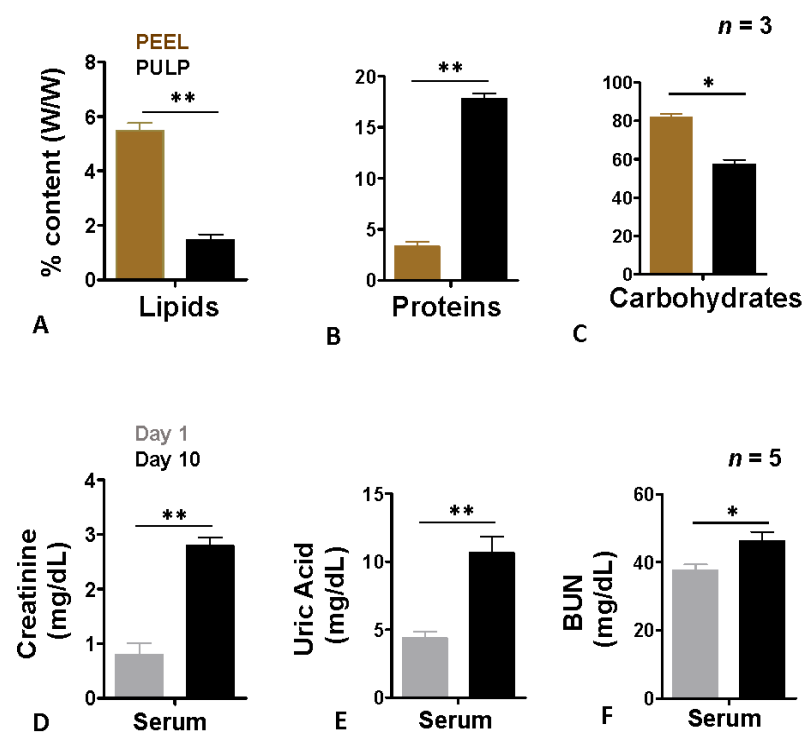

Fig. 1. Primary metabolites in Cucumis melo L. and establishment of mice model of kidney stone formation. Lipids (A), proteins (B) and carbohydrates (C) in peel (brown bars) and pulp (black bars) of Cucumis melo L. serum creatinine (D), uric acid (E) and BUN (blood urea nitrogen) (mg/dL) (F) levels at day1 (grey bars) and day 10 (black bars) after intraperitoneal injections of ethylene glycol $(0.75 \% \mathrm{~V} / \mathrm{V})$.

The total content of various secondary metabolites in both peel and pulp are listed in Table II. 
Table II. Secondary metabolites in peel and pulp of Cucumis melo L. using different extracting solvents.

\begin{tabular}{lllllll}
\hline Analytes (W/W) & Petroleum ether & Chloroform & Methanol & Ethanol & Aqueous & p-values \\
\hline Extracts of peel (mg/g) & & & & & & \\
Total polysaccharides & $25.8 \pm 0.3$ & $20.6 \pm 0.3$ & $20.1 \pm 0.2$ & $26.3 \pm 0.1$ & $23.3 \pm 0.2$ & $0.0156^{*}$ \\
Total polyphenols & $78.8 \pm 5.3$ & $101.8 \pm 0.8$ & $101.3 \pm 0.7$ & $75.5 \pm 0.6$ & $101.6 \pm 0.2$ & $0.0091^{*}$ \\
Total flavonoids & $3.9 \pm 0.2$ & $10.3 \pm 0.1$ & $3.27 \pm 0.88$ & $33.1 \pm 0.1$ & $3.4 \pm 1.3$ & $0.0121^{*}$ \\
Extracts of pulp (mg/g) & & & & & \\
Total polysaccharides & $33.7 \pm 0.3$ & $22.3 \pm 0.2$ & $29.1 \pm 0.2$ & $23.4 \pm 0.1$ & $20 \pm 0.2$ & $0.019^{*}$ \\
Total polyphenols & $117.6+0.5$ & $74.1 \pm 0.2$ & $106.1 \pm 0.4$ & $97 \pm 0.3$ & $94.6 \pm 0.4$ & $0.011^{*}$ \\
Total flavonoids & $3.7 \pm 0.4$ & $6.3+0.4$ & $3.9+0.5$ & $11.3 \pm 0.2$ & $1.7 \pm 0.3$ & $0.012^{*}$ \\
\hline
\end{tabular}

p-values, $* \leq 0.05$

Data suggested that total secondary metabolites, total polysaccharides, polyphenols and flavonoids were significantly different in various extracting solvents, petroleum ether, chloroform, methanol, ethanol and aqueous for both peel and pulp. In peel of the plant, highest total polysaccharides were observed in ethanol and petroleum ether, maximum total polyphenols were found in chloroform, methanol and aqueous extracts, while, total flavonoids were maximal in ethanol extract. In pulp of the plant, highest polysaccharides were found in petroleum ether, maximum total polyphenols in methanol and highest flavonoids in ethanol (Table II).

\section{Establishment of renal calculi in mice - a pilot study}

To test the various extracts of peel and pulp for their anti-urolithiatic potential, renal calculi were induced in mice as described in method section. A pilot study was conducted in this regard to confirm the kidney stone mice model as evident by changes in renal function after the formation of renal calculi in mice (Fig. 1D-F). Analysis of serum samples for creatinine, uric acid and BUN demonstrated a significant increase in all the three parameters after 10 days of induction of renal calculi in mice (Fig. 1D-F).

\section{Anti-urolithitic activity of peel and pulp of Cucumis melo $L$.}

Next, we examined the anti-urolithiatic activity of extracts of peel and pulp of Cucumis melo L. Data suggested that among all the extracts of peel, even compared to positive control, chloroform and methanol extracts exhibited higher potential to reduce renal calculi as evident by reduced levels of serum creatinine, uric acid and blood urea nitrogen (BUN) (Fig. 2). Whereas, among all the extracts of pulp, only chloroform extract exhibited a significant improvement in serum creatinine and uric acid levels (Fig. 2).
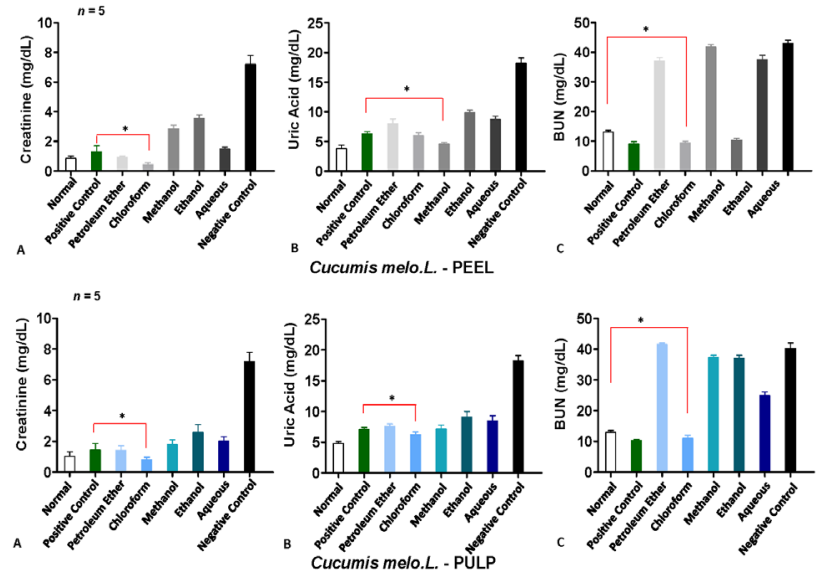

Fig. 2. Anti-urolithiatic activity of extracts of peel and pulp of Cucumis melo L. Serum creatinine levels (mg/dL) (A), serum uric acid levels $(\mathrm{mg} / \mathrm{dL})(\mathrm{B})$ and serum BUN levels $(\mathrm{mg} / \mathrm{dL})(\mathrm{C})$. White bars represent normal samples, green bars represent positive control and black bars represent negative control. * indicates $p$-values of $\leq 0.05$.

\section{DISCUSSION}

Despite recent advancements in medical sciences, recurrence of urolithiasis is still a major concern, urging many patients to resort to alternative system of treatments, such as traditional plants (Atmani et al., 2003). Thus require unwaning research on such valued plants. In the present study we investigated the antiurolithiatic activity of peel and pulp of Cucumis melo L. having numerous traditional uses, including regulation of kidney functions (Zaman et al., 2017; Varghese et al., 2013). Data demonstrated that significant differences exist in primary and secondary metabolites between pulp and peel and among various extractives obtained from different extracting solvents within peel and pulp. Moreover, after successful development of urolithiasis mice model, 
even compared to the positive control, cytosine syrup, chloroform and methanol extracts exhibited potent antiurolithiatic activity as evident from serum creatinine, uric acid and BUN levels.

Cucumis melo L. is among the most widely consumed and exported fresh fruits worldwide, yet only pulp is consumed, while peel is often discarded (Rolim et al., 2018). In this regard, in developing countries like Pakistan, plant derived treatments are still considered the safest, economical and better choices in disease conditions like urolithiasis and others, as evident from the traditional uses of Cucumis melo L. (Asif et al., 2014). The various pharmacological effects of Cucumis melo L. has been attributed to the presence of phenolic compounds, flavonoids, triterpenoids and cucurbitacin B (Lakshmi, 2014). We observed that both peel and pulp contained abundant amount of polyphenols in chloroform and petroleum ether extractives, respectively. These polyphenols, phenolic acid, flavonoids and tannins, may be related to several pharmacological effects including defense, bactericidal, anti-fungal, anti-oxidant, antiinflammatory, astringent and anti-proliferative (Rolim et al., 2018). Additionally, abundance of polysaccharides were observed in ethanol extractive of peel and petroleum ether extractive of pulp-polysaccharides have been shown to possess immune-modulatory properties affecting inflammatory responses which may appease further narrowing of ureter due to stone formation (Crowley et al., 1990).

In renal calculi the glomerular filtration rate (GFR) decreases due to obstruction of outflow of urine and due to this nitrogenous waste product such as urea, uric acid and BUN get accumulated in blood (Kishore et al., 2013). Enhanced serum levels of creatinine, uric acid and BUN are indicators of renal stones. In ethylene glycol induced mouse model of renal calculi, among all the extractives of peel, methanol and chloroform extractives demonstrated significantly larger reductions in renal calculi as evident from serum creatinine, uric acid and BUN levels. Likewise, among pulp extractives, only chloroform extracts demonstrated significant improvement in renal functions an effect comparable or even better than the standard treatment of cystone syrup (Rafiq et al., 2012) These remarkable effects of Cucumismelo L., extractives of peel and pulp might be attributed to several extracting constituentsor direct effects on kidney and ureter levels, such as restoration of urinary phosphate and lowering calcium levels to prevent stone formation (Dharmalingam et al., 2014).presence of triterpinoids might reduce the risk of stone formation by reducing inflammatory responses affecting tissue damage and by diluting urinary stone forming constituents (Manjula et al., 2012; Ashok et al., 2010) and due the effects of flavonoids which have been shown to prevent calcium oxalate super saturation and its deposition in renal tubules (Khoei et al., 2009). Another probable reason could be the effects of extractives, flavonoids and phenols, on muscarinic receptors in bladder muscles along with other mechanisms (Musa et al., 2007; Vyas and Argal, 2013) yet to be explored. However, this study provides a base for further more sophisticated studies aimed at delineating the extractives potential constituents and elated molecular mechanisms behind anti-urolithiatic effects.

\section{CONCLUSION}

In conclusion, data from the present study suggested that chloroform extractives of both peel and pulp exhibited anti-urolithiatic activity in mice model of kidney stone formation. While methanol extractives of peel exhibited anti-urolithiatic activity even better than positive control a product that is often discarded. Thus, further studies should be conducted utilizing chloroform extracts of peel of Cucumis melo L. to identify the constituents exhibiting anti-urolithiatic activity in order to identify lead molecules for future studies towards likely drug formulation.

Statement of conflict of interests

The authors have declared no conflict of interests.

\section{REFERENCES}

Ahmed, S., Hasan, M.M. and Mahmood, Z.A., 2016. Antiurolithiatic plants: Multidimensional pharmacology. J. Pharmacog. Phytochem., 5: 4-24.

Ashok, P., Koti, B.C. and Vishwanathswamy, A., 2010. Antiurolithiatic and antioxidant activity of Mimusops elengi on ethylene glycol-induced urolithiasis in rats. Indian J. Pharmacol., 42: 380-383. https://doi. org/10.4103/0253-7613.71925

Asif, H.M., Rehman, S.U., Akram, M., Akhtar, N., Sultana, S. and Rehman, J.U., 2014. Medicinal properties of Cucumis melo Linn. RADS J. Pharm. pharmacuet. Sci., 2: 58-62.

Atmani, F., Slimani, Y., Mimouni, M. and Hacht, B., 2003. Prophylaxis of calcium oxalate stones by Herniaria hirsuta on experimentally induced nephrolithiasis in rats. BJU Int., 92: 137-140. https://doi.org/10.1046/ j.1464-410X.2003.04289.x

Saleem, B., Saeed, H., Imtiaz, F., Asghar, M., Saleem, Z., Mehmood, A. and Naheed, S., 2018. Investigations of Acacia modesta Wall. leaves for in-vitro antidiabetic, proliferative and cytotoxic effects. Brazil. J. Pharm. Sci., 54: e17467. https://doi.org/10.1590/ s2175-97902018000217467

Chang, C.-C., Yang, M.-H., Wen, H.-M. and Chern, 
J.-C., 2002. Estimation of total flavonoid content in propolis by two complementary colorimetric methods. J. Fd. Drug Anal., 10: 178 - 182.

Crowley, A.R., Byrne, J.C., Vaughan Jr, E.D. and Marion, D.N., 1990. The effect of acute obstruction on ureteral function. J. Urol., 143: 596-599. https://doi. org/10.1016/S0022-5347(17)40037-1

Dharmalingam, S.R., Madhappan, R., Chidambaram, K., Ramamurthy, S., Gopal, K., Swetha, P. and Kumar, K.S., 2014. Anti-urolithiatic activity of Melia azedarach Linn leaf extract in ethylene glycolinduced urolithiasis in male albino rats. Trop. $J$. Pharm. Res., 13: 391-397. https://doi.org/10.4314/ tjpr.v13i3.12

Galib, B., Behera, K. and Kar, A., 2006. Lithiotripic activity of swadamstradi kwatha seadamstradi chan Vati-an experimantal evaluation. J. Drug Res. Ayurv. Sci., 27: 8-18.

Jagannath, N., Chikkannasetty, S.S., Govindadas, D. and Devasankaraiah, G., 2012. Study of antiurolithiatic activity of Asparagus racemosus on albino rats. Indian J. Pharmacol., 44: 576-579. https://doi. org/10.4103/0253-7613.100378

Khoei, A., Hadjzadeh, Z. and Parizady, M., 2009. Ethanolic extract of Nigella sativa L. seeds on ethylene glycol-induced kidney calculi in rats. Urol. $J ., 4:$ 86-90.

Kishore, D., Moosavi, F. and Varma, R., 2013. Effect of ethanolic extract of Portulaca oleracea Linn. on ethylene glycol and ammonium chloride induced urolithiasis. Int. J. Pharm. pharmacuet. Sci., 5: 134140.

Knoll, T., 2010. Epidemiology, pathogenesis, and pathophysiology of urolithiasis. Eur. Urol. Suppl., 9: 802-806. https://doi.org/10.1016/j. eursup.2010.11.006

Lakshmi, N., 2014. Antilithiatic ethnomedicinal plants used by the native people of anantapur district, Ap. Int. J. Res. appl. nat. soc. Sci., 2: 61 - 67.

Lowry, O.H., Rosebrough, N.J., Farr, A.L. and Randall, R.J., 1951. Protein measurement with the Folin phenol reagent. J. biol. Chem., 193: 265-275.

Makasana, A., Ranpariya, V., Desai, D., Mendpara, J. and Parekh, V., 2014. Evaluation for the anti-urolithiatic activity of Launaea procumbens against ethylene glycol-induced renal calculi in rats. Toxicol. Rep., 1: 46-52. https://doi.org/10.1016/j.toxrep.2014.03.006

Manjula, K., Rajendran, K., Eevera, T. and Kumaran, S., 2012. Effect of Costus igneus stem extract on calcium oxalate urolithiasis in albino rats. Urol. Res., 40: 499-510. https://doi.org/10.1007/s00240012-0462-6
Musa, K., Ahmed, A., Ibrahim, G., Ojonugwa, O., Bisalla, M., Musa, H. and Danmalam, U., 2007. Toxicity studies on the methanolic extract of Portulaca oleracea L. (Fam. Portulacaceae). J. biol. Sci., 7: 1293-1295. https://doi.org/10.3923/ jbs.2007.1293.1295

Parle, M. and Singh, K., 2012. Musk melon in the role of a memory melon. Annls Pharm. pharmacuet. Sci., 3: 36-41.

Pawar, A.T. and Vyawahare, N.S., 2015. Anti-urolithiatic activity of standardized extract of Biophytum sensitivum against zinc disc implantation induced urolithiasis in rats. J. Adv. Pharm. Technol. Res., 6: 176-182. https://doi.org/10.4103/2231-4040.165017

Rafiq, M., Viswanatha, G., Mohammed Azeemuddin, M., Suryakanth, D., Uday Kumar, V. and Patki, P., 2012. Cystone, a well-known herbal formulation improves renal function in rats with acute renal failure (ARF) induced by Glycerol intoxication. Iranian $J$. Pharmacol. Ther., 11: 40-40.

Rolim, P., Fidelis, G., Padilha, C., Santos, E., Rocha, H. and Macedo, G., 2018. Phenolic profile and antioxidant activity from peels and seeds of melon (Cucumis melo L. var. reticulatus) and their antiproliferative effect in cancer cells. Brazil. J. med. biol. Res., 51: e6069. https://doi.org/10.1590/1414$431 \times 20176069$

Slinkard, K. and Singleton, V.L., 1977. Total phenol analysis: Automation and comparison with manual methods. Am. J. Enol. Vitic., 28: 49-55.

United States Pharmacopoeia (USP), 2005. D-1, Volume (1). Thomas PDR. Micromedex Drug Information for the Health Care Professional.

Varghese, G., John, D. and Habtemariam, S., 2013. Medicinal plants for kidney stone: A monograph. LAP Lambert Academic Publishing.

Vyas, N. and Argal, A., 2013. Antiurolithiatic activity of extract and oleanolic acid isolated from the roots of Lantana camara on zinc disc implantation induced urolithiasis. Int. School Res. Notic. Pharmacol., 2013: 951795 . https://doi.org/10.1155/2013/951795

Wright, C., Van-Buren, L., Kroner, C. and Koning, M., 2007. Herbal medicines as diuretics: A review of the scientific evidence. J. Ethnopharmacol., 114: 1-31. https://doi.org/10.1016/j.jep.2007.07.023

Zaman, R., Alam, A., Jafri, M., Sofi, G. and Ahmad, G., 2017. Nephroprotective effect of Beekh Kasni (Roots of Cichorium intybus) in the form of methanolic and aqueous extract in Gentamycin induced rat models. J. Pharmacogn. Phytochem., 6: 337-341. 